\title{
High Prevalence of Left Ventricle Diastolic Dysfunction in Severe COPD Associated with A Low Exercise Capacity: A Cross-Sectional Study
}

\author{
Marta López-Sánchez ${ }^{1,2}$, Mariana Muñoz-Esquerre ${ }^{1,3}$, Daniel Huertas ${ }^{1}$, José Gonzalez-Costello³, Jesús \\ Ribas $^{1,3}$, Federico Manresa ${ }^{1,3}$, Jordi Dorca ${ }^{1,3}$, Salud Santos ${ }^{1,3^{*}}$ \\ 1 Department of Pulmonary Medicine, Hospital Universitari de Bellvitge, Barcelona, Spain, 2 Department of Cardiology, Hospital Universitari de Bellvitge, \\ Barcelona, Spain, 3 Pneumology Research Group, Institut d'Investigacions Biomèdiques de Bellvitge (IDIBELL), Universitat de Barcelona, Barcelona, Spain
}

\begin{abstract}
Background: A subclinical left ventricle diastolic dysfunction (LVDD) has been described in patients with chronic obstructive pulmonary disease (COPD).

Objectives: To evaluate the prevalence of LVDD in stable severe COPD patients, to analyze its relationship with exercise capacity and to look for its possible causes (lung hyperinflation, ventricular interdependence or inflammatory mechanisms).

Methods: We evaluated 106 consecutive outpatients with severe COPD (FEV 1 between $30-50 \%)$. Thirty-three (31\%) were excluded because of previous heart disease. A pulmonary function test, a 6-minute walking test (6MWT), a Doppler echocardiography test, including diastolic dysfunction parameters, and an analysis of arterial blood gases, NT-proBNP and serum inflammatory markers (CRP, leucocytes), were performed in all patients.

Results: The prevalence of LVDD in severe stable COPD patients was $90 \%$ (80\% type I, n=57, and $10 \%$ type II, $\mathrm{n}=7$ ). A significant association between a lower E/A ratio (higher LVDD type I) and a lower exercise tolerance (6minute walked distance $(6 M W D)$ ) was found $(r=0.29, p<0.05)$. The fully adjusted multivariable linear regression model demonstrated that a lower E/A ratio, a DLCO in the quartile $4^{\text {th }}$ and a higher tobacco consumption were associated with a lower 6MWD $(76,57$ and 0.7 metres, respectively, $\mathrm{p}<0.05)$. A significant correlation between E/A ratio and $\mathrm{PaO}_{2}$ was observed $(r=0.26, p<0.05)$, but not with static lung hyperinflation, inflammation or right ventricle overload parameters.
\end{abstract}

Conclusion: In stable severe COPD patients, the prevalence of LVDD is high and this condition might contribute in their lower exercise tolerance. Hypoxemia could have a concomitant role in their pathogenesis.

Citation: López-Sánchez M, Muñoz-Esquerre M, Huertas D, Gonzalez-Costello J, Ribas J, et al. (2013) High Prevalence of Left Ventricle Diastolic Dysfunction in Severe COPD Associated with A Low Exercise Capacity: A Cross-Sectional Study. PLoS ONE 8(6): e68034. doi:10.1371/journal.pone. 0068034

Editor: Henrik Watz, Pulmonary Research Institute at LungClinic Grosshansdorf, United States of America

Received February 11, 2013; Accepted May 24, 2013; Published June 27, 2013

Copyright: @ 2013 López-Sánchez et al. This is an open-access article distributed under the terms of the Creative Commons Attribution License, which permits unrestricted use, distribution, and reproduction in any medium, provided the original author and source are credited.

Funding: Supported by grants from the Societat Catalana de Pneumologia (SOCAP) 2010, Fundació Catalana de Pneumologia (FUCAP 2011-12) and Sociedad Española de Neumología y Cirugía Torácica (SEPAR) 2012. The funders had no role in study design, data collection and analysis, decision to publish, or preparation of the manuscript.

Competing interests: The authors have declared that no competing interests exist.

*E-mail: saludsantos@bellvitgehospital.cat

\section{Introduction}

Chronic obstructive pulmonary disease (COPD) is associated with relevant extrapulmonary effects and comorbidities that may influence the course of the disease [1]. Cardiovascular disorders are among the most prevalent. In fact, COPD is considered an independent cardiovascular risk factor [2,3] and ischemic heart disease is one of the main causes of mortality in COPD [4]. Coexistence of both diseases is very common and has diagnostic, therapeutic and prognostic implications $[5,6]$.

In COPD, the airflow obstruction is the major factor limiting exercise tolerance, but patients with similar $\mathrm{FEV}_{1}$ often have different degrees of dyspnea and exercise capacity, meaning that there might be other factors involved. In a previous study conducted in elderly COPD patients, the prevalence of unrecognized heart failure was over $20 \%$, and isolated diastolic heart failure was involved in half of these cases [7]. However, 
little is known about its accurate prevalence in systematic studies and its effect on the exercise capacity.

In severe emphysema, smaller cardiac cavities and lower left ventricular (LV) end-diastolic volumes (measured by Magnetic Resonance Imaging (MRI)) have been previously reported [8]. More recently, echocardiographic findings have demonstrated a subclinical LV filling impairment, specially associated with the lung static hyperinflation [9]. Moreover, LV volumes improved in patients with severe emphysema who had undergone lung volume reduction surgery $[10,11]$. All these evidences suggest that hyperinflation plays a role, at least in advanced stages of the disease. However, a relationship between LV diastolic filling and a percentage of emphysema has also been observed in patients with mild flow obstruction (without hyperinflation) [12]. This means that other pathogenetic causes of impaired LV filling should be investigated. Loss of vascular bed or inflammatory mechanisms associated with COPD are postulated as potential additional factors.

The aim of our study was to determine the prevalence of LVDD as assessed by Doppler echocardiography in a cohort of stable severe COPD patients. We also analyzed its impact on functional capacity and its relation to lung hyperinflation, right ventricular (RV) function or inflammatory parameters.

\section{Methods}

\section{Subjects and Study Design}

A cross-sectional study of a prospective cohort of consecutive patients with stable severe COPD, who were evaluated between March 2010 and May 2011 at the Pulmonary Department of Bellvitge University Hospital (Hospitalet de Llobregat, Barcelona, Spain), was performed. Severe COPD was defined as forced expiratory volume in one second $\left(\mathrm{FEV}_{1}\right)$ between $30-50 \%$ of reference value, with a ratio of $\mathrm{FEV}_{1}$ to $\mathrm{FVC}$ (forced vital capacity) below 0.70 , according to the established criteria of the Global Initiative for Chronic Obstructive Lung Disease guidelines (GOLD) [13]. For the purpose of our study, patients with a previous history of coronary heart disease, heart valve disease, symptomatic peripheral artery disease, atrial fibrillation or with a Charlson score of more than 5 were excluded. A Doppler echocardiogram, complete lung function tests, a 6-minute walking test (6MWT) and blood samples and arterial gases analysis were performed at stable stage. Patients were considered to be in stable stage when they did not require changes in their regular medication for at least six weeks. Clinical and demographic data, specifically cardiovascular risk factors, were collected. The study protocol was approved by our institution's local ethics committee ("Comité Ėtic d'Investigació Clínica de l'Hospital Universitari de Bellvitge", number PR258/09) and written informed consent was obtained from every subject.

\section{Blood Samples}

Routine tests were done for blood count, inflammatory markers (leukocytes and C-reactive protein (CRP)), N-terminal pro-B-type natriuretic peptide (NT-proBNP) and analysis of arterial blood gases.

\section{Pulmonary Function}

Pre- and post-bronchodilator spirometry (performed $15 \mathrm{~min}$ after administration of $400 \mu \mathrm{g}$ of inhaled salbutamol), static lung volumes by plethysmography and single-breath carbon monoxide diffusing capacity (DLCO) were measured according to ATS/ERS recommendations using established reference values [14].

\section{Cardiac Function}

Transthoracic echocardiographic studies were performed using a standard device (Vivid 7, General Electrics, USA). Measurements were done at least twice by the same operator and were performed at rest and at end-expiration. Due to the inherent difficulty of obtaining a good image quality of these patients, two experienced sonographers reported the studies. All records were considered technically acceptable to measure diastolic dysfunction parameters.

Images comprising 2-dimensional views from parasternal long-axis, mid-ventricular short-axis, and two and four chambers views were collected. LV wall thickness, LV enddiastolic and end-systolic diameters, RV diameter and left and right atrium areas were measured according to current recommendations. Measurement of left ventricular ejection fraction (LVEF) was performed by M-mode echocardiography using the Teicholtz method, by quantitative 2-D (biplane Simpson) method, and by 2-D visually estimated method. Parameters obtained from Doppler analysis were: peak flow velocity of early diastolic filling ( $E$ wave), peak flow velocity of late atrial filling (A wave) (both with and without Valsalva maneuver), pulse-wave Doppler of pulmonary venous flow when available and septal and lateral annular tissue Doppler velocities (septal and lateral e'). Estimation of the systolic pulmonary artery pressure (sPAP) was done using the modified Bernoulli equation with an estimated right atrial pressure of 10 $\mathrm{mmHg}$. Tricuspid annular plane systolic excursion (TAPSE) was collected as variable related to RV function.

LV diastolic function was assessed by the following variables: deceleration time of the early transmitral flow (DT), ratio of early $(E)$ to late $(A)$ transmitral filling velocities (E/A ratio) and changes with the Valsalva maneuver. It was classified as normal or diastolic dysfunction (DD) type I (impaired relaxation), type II (pseudonormal filling) or type III (restrictive filling), as previously described [15]. These guidelines were specifically used because all patients had a normal left atrial (LA) diameter. To better evaluate LV diastolic function and LV filling pressures, additional parameters obtained from tissue Doppler analysis, such as septal and lateral e' and LV filling index (E/e' ratio) were also considered. Diastolic function classification was a consensus of both sonographers.

\section{Functional Exercise Capacity}

The 6MWT was conducted according to current guidelines [16]. Supplemental oxygen was used when patient had prior chronic respiratory failure with domiciliary therapy. 
Table 1. Patient characteristics.

\begin{tabular}{|c|c|c|c|}
\hline Variables & All patients $(n=71) N$ & Non LVDD & ) LVDD $(n=64)$ \\
\hline Age, years & $65.5 \pm 7.5$ & $52.9 \pm 9.3$ & $66.9 \pm 5.8^{*}$ \\
\hline Males, n (\%) & $65(91.5)$ & $5(71.4)$ & $60(93.8)$ \\
\hline $\mathrm{BMI}, \mathrm{Kg} / \mathrm{m}^{2}$ & $27.6 \pm 5.1$ & $24.0 \pm 5.3$ & $27.9 \pm 5.0$ \\
\hline Pack-years of smoking, $n$ & $57.8 \pm 24.7$ & $48.6 \pm 22.1$ & $58.8 \pm 24.9$ \\
\hline Current smokers, n (\%) & $7(9.9)$ & $2(28.6)$ & $5(7.8)$ \\
\hline Diabetes mellitus, n (\%) & $13(18.3)$ & & $13(20.3)$ \\
\hline Dyslipidemia, n (\%) & $17(23.9)$ & & $17(23.9)$ \\
\hline Systemic hypertension, n (\%) & $29(40.8)$ & $2(28.6)$ & $27(42.2)$ \\
\hline Use of statins, $n(\%)$ & $13(18.3)$ & & $13(18.3)$ \\
\hline Use of ACEls or ARBs, $n(\%)$ & $22(31)$ & $2(28.6)$ & $20(31.3)$ \\
\hline \multicolumn{4}{|c|}{$\begin{array}{l}\text { Definition of abbreviations: } \mathrm{LVDD}=\text { Left ventricle diastolic dysfunction; } \mathrm{BMI}=\text { body } \\
\text { mass index; } \mathrm{ACEI}=\text { angiotensin-converting enzyme inhibitor; } \mathrm{ARA}=\text { angiotensin } \\
\text { receptor antagonist. Values are expressed as mean } \pm \text { standard deviation or } \\
\text { frequencies and percentages. }{ }^{*} \mathrm{p}<0,05 \text {. }\end{array}$} \\
\hline
\end{tabular}

\section{Statistical Analysis}

Data were expressed as mean \pm SD or as median and interquartile range according to whether the variable followed a normal distribution (Kolmogorov-Smirnov test). Student t test or Mann-Whitney $U$ test were used for comparisons of variables between groups, when appropriate. Categorical variables were expressed as frequencies and percentages. Correlations between variables were analyzed with Pearson's coefficient. A $p$ value of $<0.05$ was considered to be statistically significant.

Association between exercise tolerance (6MWD) and LVDD parameters (E/A ratio) were analyzed using multivariate linear regression models adjusted for potential covariates which can affect the exercise capacity, such as age, smoking history (pack years), $\mathrm{PaO}_{2}, \mathrm{FEV}_{1}$ or inspiratory-to-total lung capacity ratio (IC/TLC ratio). Data analysis was performed with the statistical SSPS software (version 18.0, Chicago, IL, USA).

\section{Results}

\section{Overall Characteristics of the Patients}

A total of 106 outpatients with stable severe COPD were evaluated during the study. Thirty-three patients (31\%) were excluded because of previous heart disease. Two additional patients were also excluded because they presented unknown moderate LV systolic dysfunction, defined as LVEF $<45 \%$ [Figure 1].

The mean age of included patients was $65 \pm 7$ years, and $91 \%(n=65)$ were male. All of them had been heavy smokers and $10 \%(n=7)$ continued to smoke. They had an elevated prevalence of cardiovascular risk factors. Table 1 shows the clinical characteristics of the study population.

All patients were continuously treated with inhaled corticosteroids, long-acting beta-agonists and anticholinergics, and short-acting beta-agonists if needed. Twenty-two percent of patients $(n=16)$ received an angiotensin-converting enzyme inhibitor and $8 \%(n=6)$ an angiotensin receptor antagonist. None of them received beta-blockers.

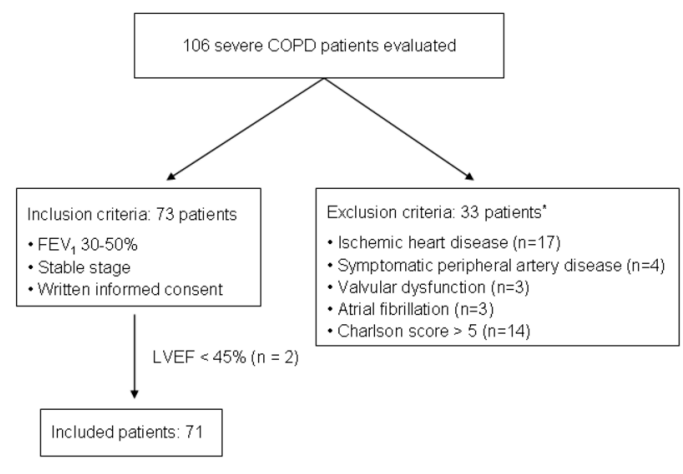

"More than one exclusion criteria were present in some patients

Figure 1. Patients evaluated during the study. doi: 10.1371/journal.pone.0068034.g001

Lung functional and analytical characteristics are given in table 2. All these patients presented severe air trapping and static lung hyperinflation. The average 6 MWD was $372 \pm 86 \mathrm{~m}$ and there was a wide range of BODE index (from 1 to 7 ). They had a mean $\mathrm{PaO}_{2}$ of $68 \pm 9 \mathrm{mmHg}$. However, $21 \%(\mathrm{n}=15)$ of patients presented chronic respiratory failure and required long-term oxygen therapy. Mean analytical measures of NTproBNP, CRP and other inflammatory markers were within the normal range.

\section{Cardiac Function}

Table 3 shows the echocardiographic parameters. The LV wall thickness, systolic and diastolic diameters, the filling volume and the stroke volume tend to be low and the LA diameter was normal in the global study population. Although SPAP and maximal tricuspid regurgitation speed $\left(\mathrm{V}_{\max }\right)$ average were in the normal range, $22 \%(n=16)$ of the patients presented echocardiographic criteria of pulmonary hypertension $(\mathrm{PH})$ (sPAP> $40 \mathrm{mmHg}$ and $\mathrm{V}_{\max } . \mathrm{T}>2.8 \mathrm{~m} / \mathrm{s}$ ). Following classical criteria, the overall prevalence of LVDD was $90 \%(n=64)(80 \%$ type I and $10 \%$ type II). Only 7 patients (10\%) presented normal DD echocardiographic parameters, so differences in clinical, functional and analytical characteristics between non LVDD and LVDD groups were not considered relevant in the analysis (Tables 2 and 3).

The prevalence of LVDD between systemic hypertension and non-systemic hypertension patients was similar. Moreover, no significant differences were found in the degree of DD, measured as E/A ratio, between two groups [Figure 2, A]. Finally, although patients over 65 years had a significantly lower E/A ratio, younger patients also had a mean E/A ratio in the range of DD [Figure 2, B].

\section{Exercise Tolerance}

A decreased walking distance in the 6MWT was associated with a lower E/A ratio $(r=0.29, p<0.05)$ and a lower septal $e^{\prime}$ $(r=0.30, p<0.05)$ [Figure 3], both indicating a higher LVDD. Additionally, in the univariate analysis, the lower 6MWD was associated with lower DLCO (quartile $4^{\text {th }}$ ) and greater tobacco 
Table 2. Lung functional and analytical characteristics.

\begin{tabular}{|c|c|c|c|}
\hline \multirow{2}{*}{$\frac{\text { Variables }}{\text { FVC, \% pred }}$} & \multicolumn{2}{|c|}{ All patients $(n=71)$ Non LVDD $(n=7)$} & \multirow{2}{*}{$\begin{array}{l}\text { LVDD (n=64) } \\
74.9 \pm 15.1\end{array}$} \\
\hline & $73.1 \pm 14.9$ & $85.9 \pm 7.5$ & \\
\hline FEV1, \% pred & $38.5 \pm 6.1$ & $36.9 \pm 4.4$ & $38.7 \pm 6.3$ \\
\hline TLC, \% pred & $127.4 \pm 23.2$ & $128.7 \pm 15.2$ & $127.2 \pm 24.1$ \\
\hline $\mathrm{RV}, \%$ pred & $216.4 \pm 76.8$ & $210.4 \pm 38.7$ & $217.1 \pm 80.5$ \\
\hline IC/TLC ratio & $0.27 \pm 0.07$ & $0.30 \pm 0.04$ & $0.27 \pm 0.07$ \\
\hline DLCO/VA, \% pred & $63.2 \pm 21.9$ & $56.1 \pm 27.2$ & $64.1 \pm 21.3$ \\
\hline $\begin{array}{l}\text { mMRC scale I-II/III, n } \\
(\%)\end{array}$ & $54(76) / 17(24)$ & $6(85.7) / 1(14.3)$ & $48(75) / 16(25)$ \\
\hline 6MWD, m & $372.1 \pm 86.4$ & $413.9 \pm 43.2$ & $367.5 \pm 88.9$ \\
\hline CRP, mg/L & $8.3 \pm 9.4$ & $1.5 \pm 0.8$ & $8.9 \pm 9.6^{*}$ \\
\hline NT-proBNP, ng/L & $79.3 \pm 70.4$ & $64.3 \pm 35.7$ & $80.8 \pm 72.9$ \\
\hline $\mathrm{PaO}_{2}, \mathrm{mmHg}$ & $68.4 \pm 9.4$ & $71.6 \pm 12.3$ & $68.1 \pm 9.0$ \\
\hline $\mathrm{PaCO}_{2}, \mathrm{mmHg}$ & $44.1 \pm 5.5$ & $44.4 \pm 5.8$ & $43.9 \pm 5.5$ \\
\hline
\end{tabular}

Definition of abbreviations: LVDD = left ventricle diastolic dysfunction; FVC = forced vital capacity; $\%$ pred $=\%$ predicted; $\mathrm{FEV}_{1}=$ forced expiratory volume in 1 second; TLC = total lung capacity; RV = residual volume; IC/TLC = inspiratory-tototal lung capacity ratio; DLCO/VA = lung diffusion capacity corrected for alveolar ventilation; $\mathrm{mMRC}=$ modified Medical Research Council dyspnea scale; $6 \mathrm{MWD}=$ 6-minute walking distance; CRP = C-reactive protein; NT-proBNP $=\mathrm{N}$-terminal proB-type natriuretic peptide. Values are expressed as mean \pm standard deviation or frequencies and percentages. ${ }^{*} p<0,05$.

Table 3. Echocardiographic parameters.

\begin{tabular}{|c|c|c|c|}
\hline \multirow{2}{*}{$\frac{\text { Variables }}{\text { Septal thickness, } \mathrm{mm}^{*}}$} & \multicolumn{3}{|c|}{ Non LVDD (n=7)LVDD Type I $(n=57)$ LVDD Type II $(n=7)$} \\
\hline & $9 \pm 2.5$ & $11 \pm 1.8$ & $10.4 \pm 1.7$ \\
\hline Posterior wall, mm & $9.8 \pm 1.4$ & $9.9 \pm 1.7$ & $9.6 \pm 1.6$ \\
\hline LVED diameter, $\mathrm{mm}^{*}$ & $48.8 \pm 5.2$ & $46.1 \pm 6.9$ & $52.9 \pm 3.7$ \\
\hline LVES diameter, $\mathrm{mm}^{*}$ & $29.8 \pm 4.3$ & $29.3 \pm 5.2$ & $34.1 \pm 3.1$ \\
\hline LA diameter, mm & $35.8 \pm 3$ & $36.6 \pm 6.7$ & $38.3 \pm 6.0$ \\
\hline LVED volume, $\mathrm{mL}^{*}$ & $63.1 \pm 17.5$ & $78.3 \pm 24.6$ & $96.3 \pm 20.2$ \\
\hline LVES volume, mL* & $21.2 \pm 9$ & $28.8 \pm 11.9$ & $36.3 \pm 9.6$ \\
\hline LV stroke volume, $\mathrm{mL}$ & $42 \pm 9$ & $49.5 \pm 14.9$ & $60.0 \pm 12.5$ \\
\hline LVEF, \% & $68.1 \pm 5.3$ & $63.6 \pm 6.8$ & $61.3 \pm 4.4$ \\
\hline sPAP, mmHg & $39.2 \pm 8.1$ & $38.7 \pm 12.6$ & $36.3 \pm 11.4$ \\
\hline TAPSE, mm & $21.3 \pm 3.7$ & $21.2 \pm 4.1$ & $23.1 \pm 2.3$ \\
\hline Basal E/A ratio* & $1.1 \pm 0.2$ & $0.7 \pm 0.2$ & $1.2 \pm 0.1$ \\
\hline Valsalva E/A ratio* & $0.8 \pm 0.1$ & $0.6 \pm 0.1$ & $0.7 \pm 0.2$ \\
\hline E/e' ratio & $7.3 \pm 1.9$ & $8.7 \pm 2.9$ & $11.5 \pm 4.9$ \\
\hline $\mathrm{DT}, \mathrm{ms}^{*}$ & $207.5 \pm 65.4$ & $257.2 \pm 62.8$ & $177.6 \pm 38.7$ \\
\hline \multicolumn{4}{|c|}{$\begin{array}{l}\text { Definition of abbreviations: LVDD = left ventricle diastolic dysfunction; LVED = left } \\
\text { ventricular end-diastolic; LVES = left ventricular end-systolic; LA = left atrium; } \\
\text { LVEF = left ventricular ejection fraction; sPAP = systolic pulmonary artery } \\
\text { pressure; TAPSE = tricuspid annular plane systolic excursion; E = peak early mitral } \\
\text { flow velocity, A = peak late mitral flow velocity; e' = velocity of mitral annulus early } \\
\text { diastolic motion; E/A ratio = ratio of early (E) to late (A) mitral flow peak velocities; } \\
\text { E/e' ratio = left ventricular filling index; DT = deceleration time of the early mitral } \\
\text { flow. Values are expressed as mean } \pm \text { standard deviation. }{ }^{*} p<0.05 \text { between non- } \\
\text { LVDD and LVDD (type I and type II) groups. }\end{array}$} \\
\hline
\end{tabular}

consumption [Table 4]. DLCO quartile $4^{\text {th }}$ is characteristic of more severe emphysema. In contrast, no association was
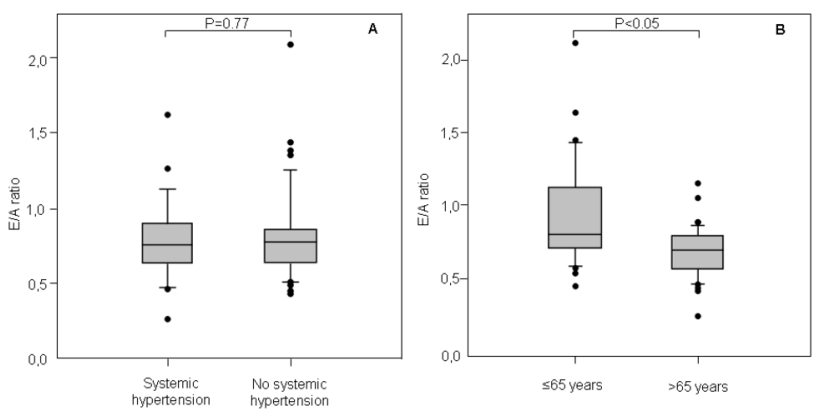

Figure 2. Individual data of the E/A ratio as measurement of the left ventricle diastolic dysfunction (LVDD). No significant differences were found in the E/A ratio between systemic hypertension and non-systemic hypertension patients (A). Although patients over 65 years had a significantly lower E/A ratio, younger patients also had a mean E/A ratio in the range of LVDD (B). Horizontal bars represent median values and box areas represent interquartile ranges. $\mathrm{E} / \mathrm{A}$ ratio $=$ ratio of early $(E)$ to late $(A)$ transmitral filling velocities. doi: 10.1371/journal.pone.0068034.g002
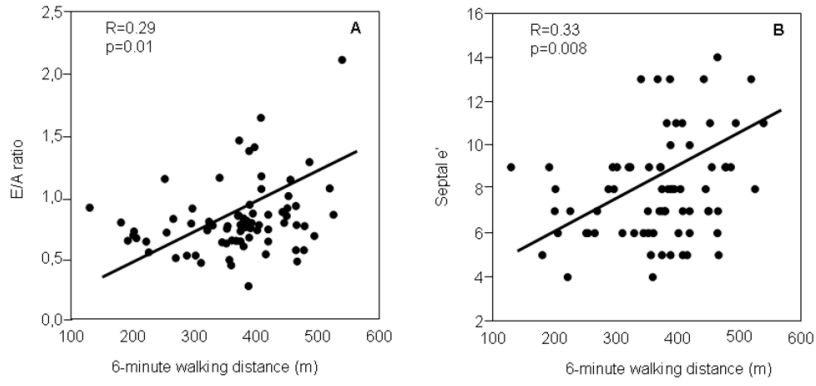

Figure 3. Relationship between the left ventricle diastolic dysfunction and the exercise tolerance in severe COPD patients. A lower 6-minute walking distance correlated with a lower $E / A$ ratio $(A)$ and a lower septal e' $(B)$. E/A ratio = ratio of early $(E)$ to late $(A)$ transmitral filling velocities.

doi: 10.1371/journal.pone.0068034.g003

found between 6MWD and other parameters that might have influenced the exercise tolerance in COPD, such as FEV 1 , the presence of $\mathrm{PH}$ (SPAP) or lung hyperinflation (IC/TLC ratio).

The fully adjusted multivariable linear regression model, with 6MWD as a dependent variable, demonstrated that for every 1 point fall in the E/A ratio, the 6MWD decreased 76m $(p<0.05)$. In addition, a DLCO in the quartile $4^{\text {th }}$ was associated with $a$ decrease of $57 \mathrm{~m}$ in the 6MWD and, for each pack-year of tobacco consumption, the distance decreased $0.78 \mathrm{~m}(p<0.05)$ [Table 5]. Age had no significant influence in any of the linear regression models. 
Table 4. Univariate analysis of clinical, lung functional and echocardiographic variables according to the 6-minute walking distance $(\mathrm{m})$.

\begin{tabular}{|c|c|c|}
\hline Variables & Coefficient $\beta$ (95\% Cl) & $p$-value \\
\hline E/A ratio & $88.2(20.4$ to 156.0$)$ & $0.012^{*} \dagger$ \\
\hline $\mathrm{PaO}_{2}, \mathrm{mmHg}$ & $1.9(-0.4$ to 4.2$)$ & $0.102 \dagger$ \\
\hline DLCO quartile $4^{\text {th }}$ & $-63.2(-110.1$ to -16.3$)$ & $0.009^{*} \dagger$ \\
\hline Smoking, pack-years & $-0.9(-1.7$ to -0.1$)$ & $0.024^{*} \dagger$ \\
\hline Age, years & $-2.5(-5.2$ to 0.2$)$ & $0.071 \dagger$ \\
\hline TAPSE, mm & $5.0(-0.2$ to 10.2$)$ & $0.060 \dagger$ \\
\hline $\mathrm{FEV}_{1}, \%$ pred & $1.0(-2.4$ to 4.4$)$ & 0.557 \\
\hline IC/TLC ratio & $3.7(-336.2$ to 343.6$)$ & 0.983 \\
\hline Diabetes & $-24.2(-77.2$ to 28.7$)$ & 0.364 \\
\hline Pulmonary hypertension & $10.3(-37.1$ to 57.6$)$ & 0.666 \\
\hline BMI, $\mathrm{kg} / \mathrm{m}^{2}$ & $-0.13(-4.2$ to 3.9$)$ & 0.948 \\
\hline Use of ACEls / ARBs & $10.7(-33.7$ to 55.2$)$ & 0.632 \\
\hline
\end{tabular}

Definition of abbreviations: $\mathrm{Cl}=$ confidence interval; $\mathrm{E} / \mathrm{A}$ ratio $=$ ratio of early $(\mathrm{E})$ to late (A) mitral flow peak velocities; DLCO = diffusing capacity for carbon monoxide; TAPSE $=$ tricuspid annular plane systolic excursion; $\mathrm{FEV}_{1}=$ forced expiratory volume in 1 second IC/TLC = inspiratory-to-total lung capacity ratio; $\mathrm{BMI}=$ body mass index; $\mathrm{ACEI}=$ angiotensin-converting enzyme inhibitor; $\mathrm{ARA}=$ angiotensin receptor antagonist; * A p value $<0.05$ was considered to be statistically significant; $t p<0.2$ was considered for the multivariate analysis.

Table 5. Multivariate analysis according to the 6-minute walking distance $(\mathrm{m})$ as dependent variable.

\begin{tabular}{lll}
\hline & & \\
\hline Independent variables & Coefficient $\boldsymbol{\beta} \mathbf{( 9 5 \%} \mathbf{C I})$ & $\boldsymbol{p}$-value \\
\hline (Constant: $368,20 \mathrm{~m})$ & & \\
E/A ratio & $76,16(12,1$ to 140,2$)$ & $0.012^{*}$ \\
Smoking, pack-years & $-0,78(-1,54$ to $-0,02)$ & $0.043^{*}$ \\
DLCO, quartile 4 ${ }^{\text {th }}$ & $-57,05(-101,3$ to $-12,8)$ & $0.021^{*}$ \\
\hline
\end{tabular}

Definition of abbreviations: $\mathrm{Cl}=$ confidence interval; $\mathrm{E} / \mathrm{A}$ ratio $=$ ratio of early $(\mathrm{E})$ to late (A) mitral flow peak velocities; DLCO = diffusing capacity for carbon monoxide.

${ }^{*} A p$ value of $<0.05$ was considered to be statistically significant.

\section{Parameters related to left ventricular diastolic dysfunction}

In our patients, no correlation was found between the degree of LVDD, as measured by E/A ratio, and levels of NT-proBNP or inflammatory blood markers (CRP, leukocytes), nor with sPAP or lung hyperinflation parameters. Instead, we found a significant correlation between LVDD, as measured by E/A ratio, and a lower $\mathrm{PaO}_{2}(r=0.27, p<0.05)$. Finally, associations with DLCO were consistent but not significant.

\section{Discussion}

The main finding of our study was the high prevalence of LVDD (90\%) in severe stable COPD patients. Although an association between increasing severity of airflow obstruction and decreased LV filling has already been described, to our knowledge this is the first study to analyze the prevalence of LVDD in a selected group of COPD patients with similar FEV 1 and static lung hyperinflation. Moreover, the impaired LV diastolic filling and the reduced LV distensibility in these patients was independently associated with a reduced exercise tolerance as measured by the 6MWD.

Age and systemic hypertension are factors directly related to LVDD in the general population. In fact, the prevalence of mild LVDD in people older than 65 years with a normal LVEF is $21.7 \%$ and this increases to $27 \%$ in those older than $70[17,18]$. In our sample of severe COPD patients, classical echocardiographic parameters of LVDD were also observed regardless of age and lack of systemic hypertension. Furthermore, we didn't find echocardiographic parameters of chronic systemic hypertension such as LV hypertrophy or LA dilation.

Echocardiography is the most usual and feasible noninvasive method to asses LV diastolic function. The E/A ratio mainly represent a measurement of LV filling. According to previous studies performed in COPD patients, a lower E/A ratio means an increased atrial contribution to this filling [19]. This occurs as well in the presence as in the absence of elevated PAP [20]. However, LVDD in COPD patients could be the result of decreased preload or pathological myocardial compliance. It is unknown which are the best echocardiographic parameters to measure LVDD. Evaluation of LV function in COPD patients may be improved using tissue Doppler echocardiography (TDE). One of the contributions of our study was to introduce tissue Doppler echocardiography (TDE) parameters, such as septal $e^{\prime}$ and E/e'ratio, which are estimated measurements of LV wall compliance.

Previous studies have already shown that physical activity in patients with COPD is reduced [21] and that, in addition to the respiratory disturbances, it could be associated with impaired LV diastolic filling [22]. In our study, the exercise tolerance was measured by the distance walked in the 6MWT, which is a validated and reproducible test that shows the maximum sustainable exercise [23]. Moreover, the 6MWT is a good predictor of mortality in COPD [24]. For patients with severe disease, the 6MWT shows marked differences between individuals, so that the current multi-dimension indexes that include this parameter, such as BODE, are better predictors than the $\mathrm{FEV}_{1}$ which are used individually [25]. We demonstrate a meaningful association between the degree of LVDD, measured as E/A ratio and/or septal e', and the exercise capacity as assessed by 6MWD, in patients with the same degree of COPD severity and significant hyperinflation. These results add importance to the cardiovascular status in the exercise capacity of severe COPD patients. Previous echocardiographic studies which address the LVDD and RV function in COPD and their relation with 6MWT present limitations, because patients with mild or moderate airflow obstruction have been selected $[9,26,27]$. Furthermore, some of the studies did not exclude other cardiovascular diseases and did not report the presence of systemic hypertension and comorbidities [26,27]. Sims et al [28] demonstrated a relationship between $\mathrm{PH}$ and a lower 6MWD in severe COPD patients. In contrast, our patients, with the same degree of severity, had lower exercise tolerance associated with higher 
LVDD, regardless of structural and functional changes of RV, measured by echocardiography.

Previous studies have shown that up to $31 \%$ of ICU admissions with a diagnosis of severe acute exacerbation of COPD might be of cardiac origin (associated with left heart dysfunction measured by echocardiography, most of the cases showing DD) and in these cases, the NT-proBNP is a serological marker that helps in clinical diagnosis [29]. BNP secretion might be secondary either to LV stress or to hypoxemia, as well as to PH or RV stress. In our stable COPD patients we did not find any relationship between the level of NT-proBNP and the degree of LVDD, hypoxemia or the presence of RV overload. So, it doesn't seem to be a good marker of LVDD in non-acute stages of the disease.

Several mechanisms might explain the presence of LVDD in COPD patients. Watz et al. [9] described a significant correlation between LVDD and static pulmonary hyperinflation measured by the IC/TLC ratio in patients with different degrees of severity of COPD. Vassaux et al [30] showed an association between resting hyperinflation and lower oxygen pulse in patients with severe COPD, suggesting that a decreased cardiac function related to hyperinflation may contribute to exercise limitation. In our study, most patients had an IC/TLC ratio below 0.25 . However, we found no significant correlation between IC/TLC ratio and echocardiographic parameters of LVDD, so hyperinflation might not be the only factor that determines LVDD in these patients.

In a high percentage of patients with advanced COPD, PH has already been described [31]. Abnormal patterns of LV diastolic filling have been reported in patients with increased $\mathrm{RV}$ afterload due to ventricular interdependence, either in idiopathic PH [32] than in PH associated with COPD [20,33,34]. Only $22 \%$ of our patients had echocardiographic criteria of $\mathrm{PH}$ (possibly underestimated), and we did not find any correlation between SPAP and LVDD parameters. However, endothelial dysfunction and vascular remodelling of pulmonary muscular arteries have been demonstrated in the entire disease spectrum, suggesting an impairment of pulmonary vessels distensibility and a subclinical increase in pulmonary vascular resistance [35,36]. These changes, together with loss of vascular bed due to emphysema, may develop decreased LV preload. In accordance with this hypothesis, a recent study has shown a link between LV filling volume, measured by MRI, and the degree of emphysema in patients with mild obstruction [12]. Interestingly, we observed a trend of association between the degree of LVDD and DLCO, a functional marker largely related to the degree of emphysema in COPD patients [37]. Some of the patients in our study ( $n=43$ ) had a computed tomography (CT) scan and, in these cases, we quantified the presence of emphysema (attenuation index lower than $950 \mathrm{HU}$ ) with a specific software. In the same way as Barr et al. [12] did in the general population, we also found that a higher emphysema index correlated with lower LV end-diastolic volume $(R=$ $-0.321, p<0.05$ ) in severe COPD patients. In contrast, LVDD parameters did not change depending on the distribution of pulmonary emphysema.

According to our results, the severity of hypoxemia significantly correlates with the degree of LVDD in severe
COPD patients. At advanced stages of the disease, hypoxemia is linked to the pathogenesis of pulmonary vascular abnormalities. In fact, Dinh-Xuan et al. [36] showed that hypoxemia is related to endothelial dysfunction. Moreover, chronic hypoxic pulmonary vasoconstriction might generate increasing pulmonary vascular resistance and a secondary decreased LV filling. Likewise, hypoxemia might also directly influence the cellular metabolism producing an impaired myocardial relaxation and higher LVDD [38].

Systemic inflammatory parameters that were measured in our patients (CRP, leucocytes) showed no association with LVDD measurements, so the inflammatory mechanism defining this disease $[39,40]$ has not been demonstrated.

One of the strengths of the study was the homogeneous group selection of severe COPD patients. We excluded those with very severe COPD, since other limiting factors may influence their exercise capacity, and those with mild/moderate obstruction severity, because they often did not have any symptoms. This narrow selection avoids the influence of the degree of obstruction $\left(\mathrm{FEV}_{1}\right)$ in the exercise tolerance.

Study limitations include the quality of echocardiography as a method to measure LVDD. Secondly, the study was performed at rest. Dynamic hyperinflation described in COPD during exercise may play a role in LVDD of these patients. Finally, our study was cross-sectional, so it is not possible to make firm conclusions about causality.

In summary, the prevalence of LVDD in patients with severe COPD is high, as assessed by standard echocardiographic measurements, even in the younger patients group and regardless of lack of systemic hypertension. These changes in LV volume filling and distensibility involve a decrease in exercise tolerance as measured by 6MWD. Besides static lung hyperinflation, other factors could be implicated in this condition. Loss of vascular bed due to emphysema, endothelial dysfunction or systemic parameters such as $\mathrm{PO}_{2}$ or inflammatory markers, also point to be causal mechanisms. Our study suggests that LVDD has clinical consequences in patients with severe COPD. However, further studies are needed to establish the causal relationship between LVDD and heart failure, one of the most prominent extrapulmonary manifestations of COPD.

\section{Acknowledgements}

The authors would like to thank C. Molina and E. Claver for their contribution in the implementation and evaluation of echocardiographic measurements; and to M.J. Manuel for their collaboration in the study oversight.

\section{Author Contributions}

Conceived and designed the experiments: MLS JGC JR FM JD SS. Performed the experiments: MLS MME DH JGC SS. Analyzed the data: MLS MME SS. Contributed reagents/ materials/analysis tools: MLS MME SS. Wrote the manuscript: MLS MME DH JGC JR FM JD SS. 


\section{References}

1. Barnes PJ, Celli BR (2009) Systemic manifestations and comorbidities of COPD. Eur Respir J 33: 1165-1185. doi: 10.1183/09031936.00128008. PubMed: 19407051

2. Schünemann HJ, Dorn J, Grant BJ, Winkelstein W, Trevisan M (2000) Pulmonary function is a long-term predictor of mortality in the general population: 29-year follow-up of the Buffalo Health Study. Chest 118: 656-664 doi:10.1378/chest.118.3.656. PubMed: 10988186.

3. Schroeder EB, Welch VL, Couper D, Nieto FJ, Liao D et al. (2003) Lung function and incident coronary heart disease: the Atherosclerosis Risk In Communities Study. Am J Epidemiol 158: 1171-1181. doi: 10.1093/aje/kwg276. PubMed: 14652302.

4. Anthonisen NR, Skeans MA, Wise RA, Manfreda J, Kanner REEet al (2005) The effects of a smoking cessation intervention on 14.5-year mortality: a randomized clinical trial. Ann Intern Med 142: 233-239. doi: 10.7326/0003-4819-142-4-200502150-00005. PubMed: 15710956.

5. Rutten FH, Moons KG, Cramer MJ, Grobbee DE, Zuithoff NP et al. (2005) Recognising heart failure in elderly patients with stable chronic obstructive pulmonary disease in primary care: cross sectional diagnostic study. BMJ 331: 1379. doi:10.1136/bmj.38664.661181.55. PubMed: 16321994

6. Rutten FH, Cramer MJ, Lammers JW, Grobbee DE, Hoes AW (2006) Heart failure and chronic obstructive pulmonary disease: an ignored combination? Eur J Heart Fail 8: 706-711. doi:10.1016/j.ejheart. 2006.01.010. PubMed: 16531114

7. Rutten FH, Cramer MJ, Grobbee DE, Sachs AP, Kirkels JH et al. (2005) Unrecognized heart failure in elderly patients with stable chronic obstructive pulmonary disease. Eur Heart J 26: 1887-1894. doi: 10.1093/eurheartj/ehi291. PubMed: 15860516.

8. Jörgensen K, Müller MF, Nel J, Upton RN, Houltz E et al. (2007) Reduced intrathoracic blood volume and left and right ventricular dimensions in patients with severe emphysema: An MRI study. Chest 131: 1050-1057. doi:10.1378/chest.06-2245. PubMed: 17426209

9. Watz H, Waschki B, Meyer T, Kretschmar G, Kirsten A et al. (2010) Decreasing cardiac chamber sizes and associated heart dysfunction in COPD: Role of hyperinflation. Chest 138: 32-38. doi:10.1378/chest. 10312. PubMed: 20190002.

10. Jörgensen K, Houltz E, Westfelt U, Nilsson F, Scherstén H et al. (2003) Effects of lung volume reduction surgery on left ventricular diastolic filling and dimensions in patients with severe emphysema. Chest 124 : 1863-1870. doi:10.1378/chest.124.5.1863. PubMed: 14605061.

11. Criner GJ, Scharf SM, Falk JA, Gaughan JP, Sternberg AL et al. (2007) Effect of lung volume reduction surgery on resting pulmonary hemodynamics in severe emphysema. Am J Respir Crit Care Med 176: 253-260. doi:10.1164/rccm.200608-11140C. PubMed: 17496227.

12. Barr RG, Bluemke DA, Ahmed FS, Carr JJ, Enright PL et al. (2010) Percent emphysema, airflow obstruction, and impaired left ventricular filling. N Engl J Med 362: 217-227. doi:10.1056/NEJMoa0808836. PubMed: 20089972.

13. Rabe KF, Hurd S, Anzueto A, Barnes PJ, Buist SA et al. (2007) Global strategy for the diagnosis, management, and prevention of chronic obstructive pulmonary disease: GOLD executive summary. Am J Respir Crit Care Med 176: 532-555. doi:10.1164/rccm.200703-456SO. PubMed: 17507545

14. Miller MR, Hankinson J, Brusasco V F, Casaburi R et al (2005) Series ATS/ERS Task Force: Standardisation of spirometry. Eur Respir J 26: 319-338. doi:10.1183/09031936.05.00034805. PubMed: 16055882

15. Rakowski H, Appleton C, Chan KL, Dumesnil JG, Honos G et al. (1996) Canadian consensus recommendations for the measurement and reporting of diastolic dysfunction by echocardiography: from the Investigators of Consensus on Diastolic Dysfunction by Echocardiography. J Am Soc Echocardiogr 9: 736-760. doi:10.1016/ S0894-7317(96)90076-0. PubMed: 8887883

16. ATS (2002) statement: guidelines for the six-minute walk test. Am J Respir Crit Care Med 166: 111-117. doi:10.1164/ajrccm.166.1.at1102. PubMed: 12091180

17. Abhayaratna WP, Marwick TH, Smith WT, Becker NG (2006) Characteristics of left ventricular diastolic dysfunction in the community: an echocardiographic survey. Heart 92: 1259-1264. doi:10.1136/hrt. 2005.080150. PubMed: 16488928.

18. Fischer M, Baessler A, Hense HW, Hengstenberg $C$, Muscholl $M$ et al. (2003) Prevalence of left ventricular diastolic dysfunction in the community. Results from a Doppler echocardiographic-based survey of a population sample. Eur Heart J 24: 320-328. doi:10.1016/ S0195-668X(02)00428-1. PubMed: 12581679

19. Boussuges A, Pinet C, Molenat F, Burnet H, Ambrosi P et al. (2000) Left atrial and ventricular filling in chronic obstructive pulmonary disease. An echocardiographic and Doppler study. Am J Respir Crit
Care Med 162: 670-675. doi:10.1164/ajrccm.162.2.9908056. PubMed: 10934104

20. Funk GC, Lang I, Schenk P, Valipour A, Hartl S et al. (2008) Left ventricular diastolic dysfunction in patients with COPD in the presence and absence of elevated pulmonary arterial pressure. Chest 133: 1354-1359. doi:10.1378/chest.07-2685. PubMed: 18339780.

21. Pitta F, Troosters T, Spruit MA Probst VS, Decramer M et al. (2005) Characteristics of physical activities in daily life in chronic obstructive pulmonary disease. Am J Respir Crit Care Med 171: 972-977. doi: 10.1164/rccm.200407-855OC. PubMed: 15665324.

22. Watz H, Waschki B, Boehme C, Claussen M, Meyer T et al. (2008) Extrapulmonary effects of chronic obstructive pulmonary disease on physical activity: a cross-sectional study. Am J Respir Crit Care Med 177: 743-751. doi:10.1164/rccm.200707-10110C. PubMed: 18048807.

23. Rabinovich RA, Vilaró J, Roca J (2004) [Evaluation exercise tolerance in COPD patients: The 6-minute walking test]. Arch Bronconeumol 40(2): 80-85. doi:10.1157/13056713. PubMed: 14746731.

24. Pinto-Plata VM, Cote C, Cabral H, Taylor J, Celli BR (2004) The 6-min walk distance: Change over time and value as a predictor of survival in severe COPD. Eur Respir J 23: 28-33. doi: 10.1183/09031936.03.00034603. PubMed: 14738227.

25. Celli BR, Cote CG, Marin JM, Casanova C, Montes de Oca M et al. (2004) The body-mass index, airflow obstruction, dyspnea, and exercise capacity index in chronic obstructive pulmonary disease $\mathrm{N}$ Engl J Med 350: 1005-1012. doi:10.1056/NEJMoa021322. PubMed: 14999112.

26. Malerba M, Ragnoli B, Salameh M, Sennino G, Sorlini ML et al. (2011) Sub-clinical left ventricular diastolic dysfunction in early stage of chronic obstructive pulmonary disease. J Biol Regul Homeost Agents 25(3): 443-451. PubMed: 22023769.

27. Cuttica MJ, Shah SJ, Rosenberg SR, Orr R, Beussink L et al. (2011) Right heart structural changes are independently associated with exercise capacity in non-severe COPD. PLOS ONE 6(12): 1-8. PubMed: 22220201.

28. Sims MW, Margolis DJ, Localio AR, Panettieri RA, Kawut SM et al. (2009) Impact of pulmonary artery pressure on exercise function in severe COPD. Chest 136: 412-419. doi:10.1378/chest.08-2739. PubMed: 19318664

29. Abroug F, Ouanes-Besbes L, Nciri N, Sellami N, Addad F et al. (2006) Association of left-heart dysfunction with severe exacerbation of chronic obstructive pulmonary disease: Diagnostic performance of cardiac biomarkers. Am J Respir Crit Care Med;174: 990-996. doi: 10.1164/rccm.200603-3800C. PubMed: 16840745.

30. Vassaux C, Torre-Bouscoulet L, Zeineldine S, Cortopassi F, Paz-Díaz $H$ et al. (2008) Effects of hyperinflation on the oxygen pulse as a marker of cardiac performance in COPD. Eur Respir J 32: 1275-1282. doi:10.1183/09031936.00151707. PubMed: 18550609.

31. Scharf SM, Iqbal M, Keller C, Criner G, Lee S et al. (2002) Hemodynamic characterization of patients with severe emphysema. Am J Respir Crit Care Med 166: 314-322. doi:10.1164/rccm.2107027. PubMed: 12153963

32. Kasner M, Westermann D, Steendijk P, Dröse S, Poller W et al. (2012) Left ventricular dysfunction induced by nonsevere idiopathic pulmonary arterial hypertension: A pressure-volume relationship studyLV. Am J Respir Crit Care Med 186: 181-189. doi:10.1164/rccm. 201110-18600C. PubMed: 22561959

33. Vonk Noordegraaf A, Marcus JT, Roseboom B, Postmus PE, Faes TJ et al. (1997) The effect of right ventricular hypertrophy on left ventricular ejection fraction in pulmonary emphysema. Chest 112 : 640-645. doi:10.1378/chest.112.3.640. PubMed: 9315795.

34. Yilmaz R, Gencer M, Ceylan E (2005) Impact of chronic obstructive pulmonary disease with pulmonary hypertension on both left ventricular systolic and diastolic performance. J Am Soc Echocardiogr 18: 873-881. doi:10.1016/j.echo.2005.01.016. PubMed: 16084341.

35. Santos S, Peinado VI, Ramirez J, Morales-Blanhir J, Bastos R et al. (2003) Enhanced expression of vascular endothelial growth factor in pulmonary arteries of smokers and patients with moderate chronic obstructive pulmonary disease. Am J Respir Crit Care Med 167: 1250-1256. doi:10.1164/rccm.200210-12330C. PubMed: 12615615.

36. Dinh-Xuan AT, Higenbottam TW, Clelland CA, Pepke-Zaba J, Cremona $G$ et al. (1991) Impairment of endothelium-dependent pulmonary-artery relaxation in chronic obstructive lung disease. $\mathrm{N}$ Engl $\mathrm{J}$ Med 324 : 1539-1547. doi:10.1056/NEJM199105303242203. PubMed: 2027358.

37. Müller NL, Staples CA, Miller RR, Abboud RT (1988) "Density mask". An objective method to quantitate emphysema using computed tomography. Chest 94: 782-787. doi:10.1378/chest.94.4.782. PubMed: 3168574 . 
38. Larsen KO, Sjaastad I, Svindland A, Krobert KA, Skjønsberg OH et al. (2006) Alveolar hypoxia induces left ventricular diastolic dysfunction and reduces phosphorylation of phospholamban in mice. Am J Physiol Heart Circ Physiol 291: H507-H516. doi:10.1152/ajpheart.00862.2005. PubMed: 16582020.

39. Peinado VI, Barberá JA, Abate P, Ramírez J, Roca J et al. (1999) Inflammatory reaction in pulmonary muscular arteries of patients with mild chronic obstructive pulmonary disease. Am J Respir Crit Care Med
159: 1605-1611. doi:10.1164/ajrccm.159.5.9807059. PubMed: 10228134.

40. Sin DD, Man SF (2003) Why are patients with chronic obstructive pulmonary disease at increased risk of cardiovascular diseases? The potential role of systemic inflammation in chronic obstructive pulmonary disease. Circulation 107: 1514-1519. doi:10.1161/01.CIR. 0000056767.69054.B3. PubMed: 12654609. 